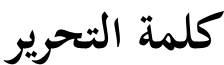

\section{مرجعية البحث في تطوّر الفكر التربوي}

\section{هيئة التحرير}

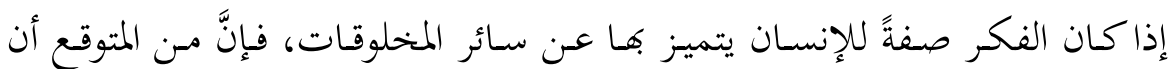

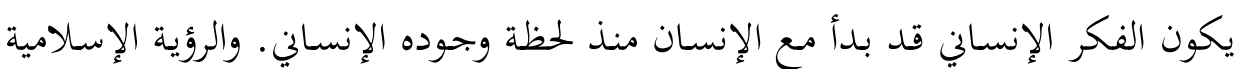

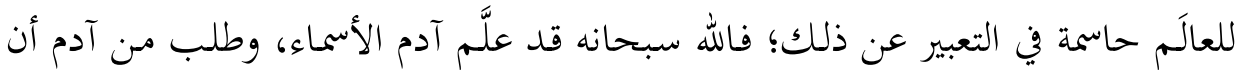

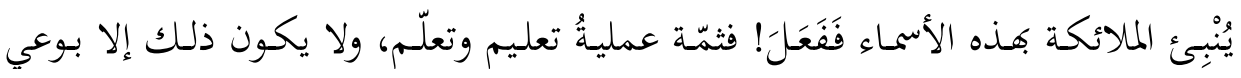

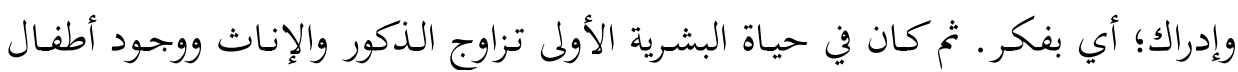

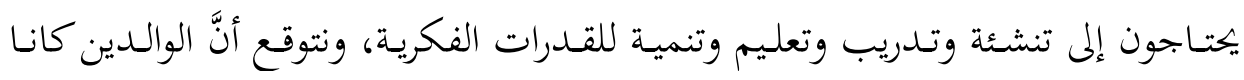

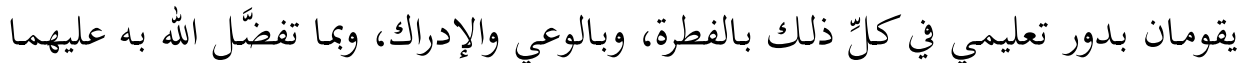

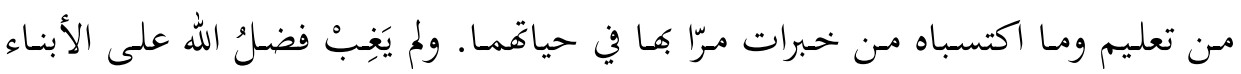

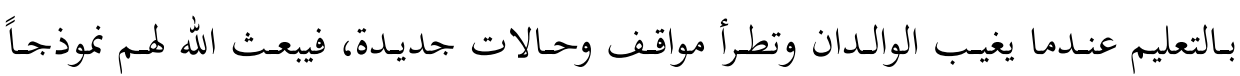

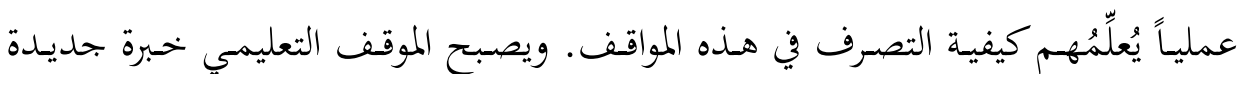

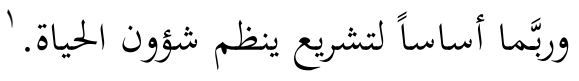

وقد ارتبط الفكر الإنساني بالعلم والتعليم، فالإنسان كان مزوداً بالقدرة على تعلُّم

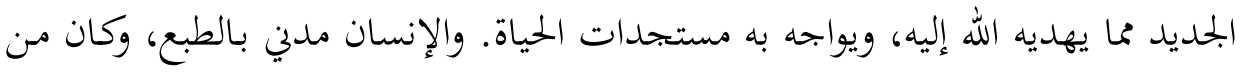

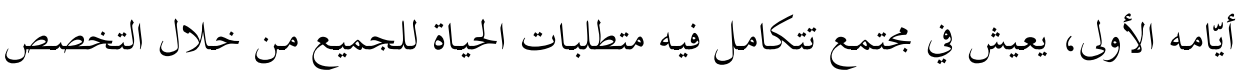

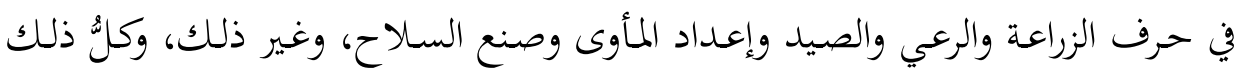

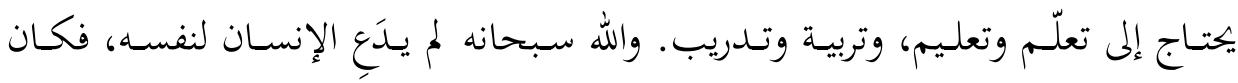

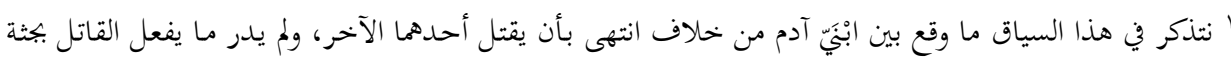

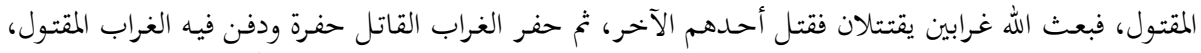

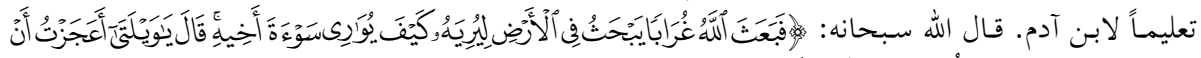

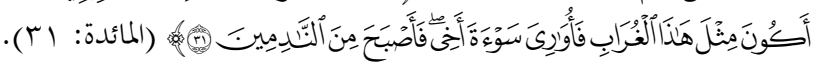


الأنبياء والرسل يقدمون لأقوامهم ما يصحح تصوراهم وأفكارهم، ويزكي نفوسهم، ويدير شؤوغم.

وبعض الأنبيـاء والأوليـاء كـانوا نمـاذج في إتقـان المهـن والحـرف، فالنَّبـيٌُ نسوحُ عليـه

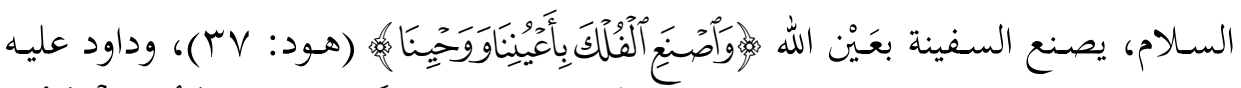

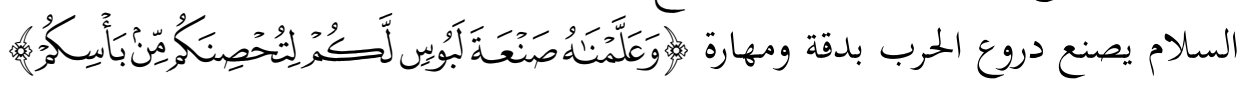

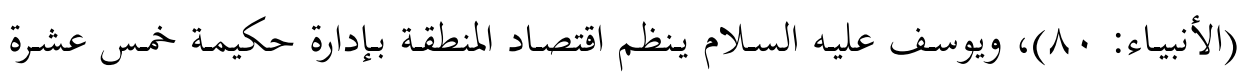

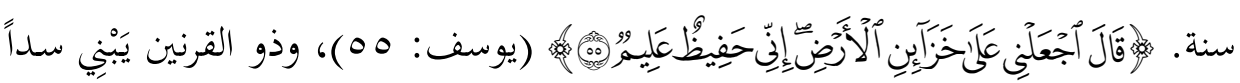

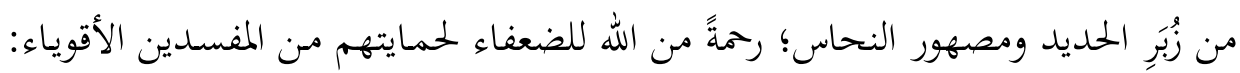
مارِ

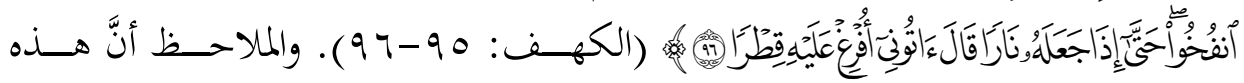

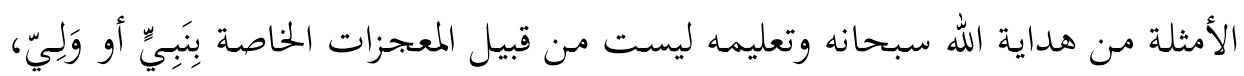

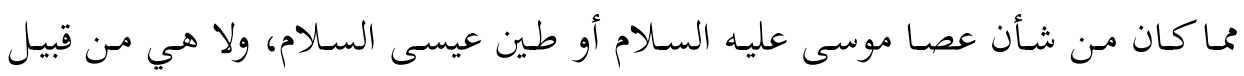

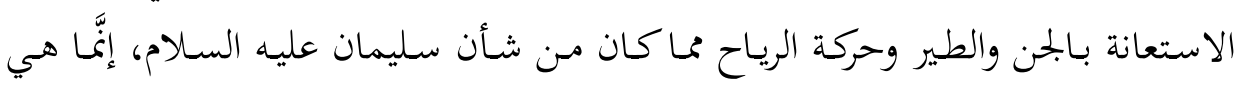
أفكار وخبرات بشرية تختص بالإداة العلمية للحياة العملية. يتعلمها الناس وفق وحت ما تستند

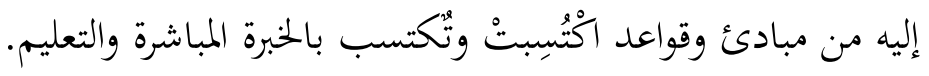

وتتوارث الأجيال البشرية بعض هذه الخبرات عن طريق التنشئة الأسرية، لا سيما ما يختص بعناصر الهوية المميزة لكل أمة مـن دين وقيم ولغة وتاريخ، كما تؤدي مؤسسات

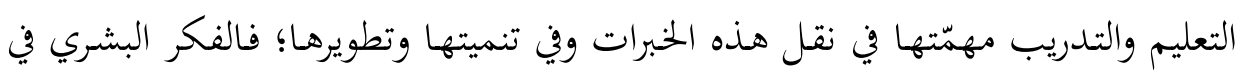

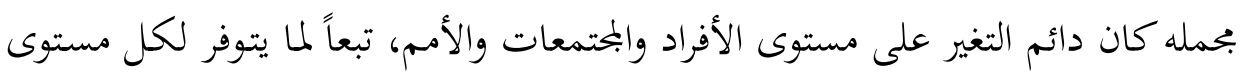

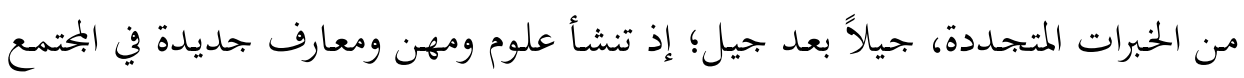
الواحلد، ويحلدث تثـاقف بين البحتمعات، في حسالات السلم والحـرب. وتتواصل عمليـات التطور والتغير في مؤسسات التعليم وموضوعاته، وأساليبه.

وتاريخ التربية فرع مـن فروع علم التربية، وهو فرع يـدرس تطور الفكر التربوي ومـا

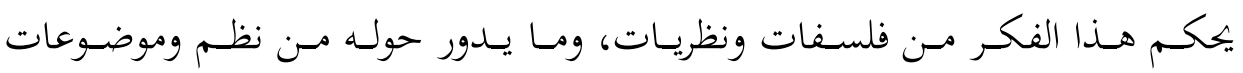




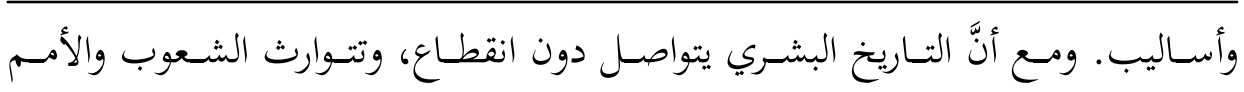

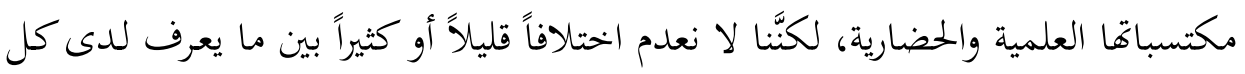

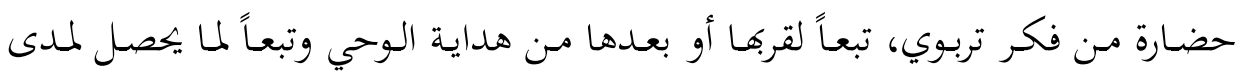
التواصل بين الحضارات المتزامنة، أو درجة التوارث بين الحضارات المبعات المتتابعة.

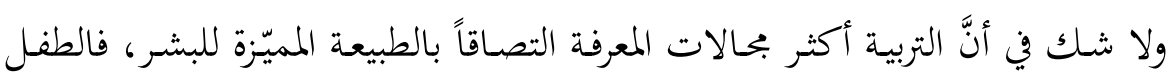

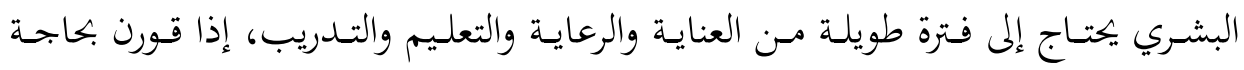

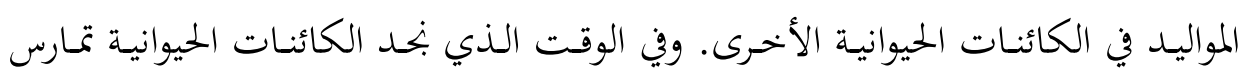

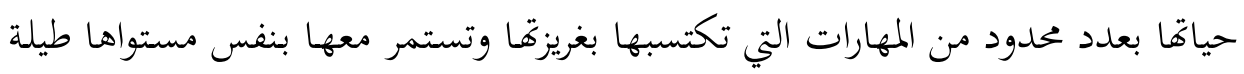

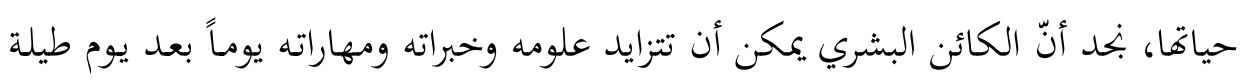

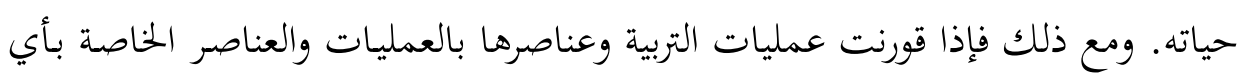

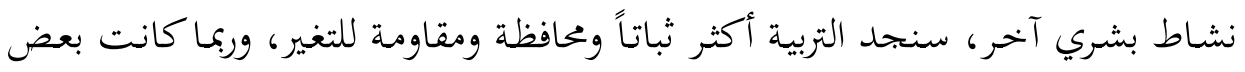

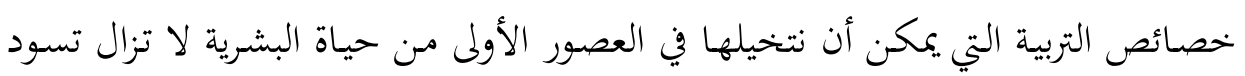

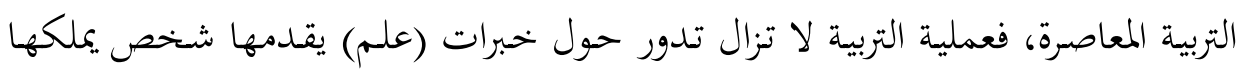

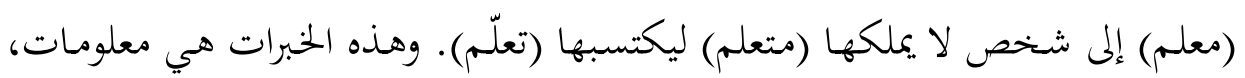

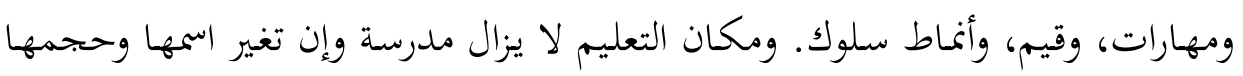

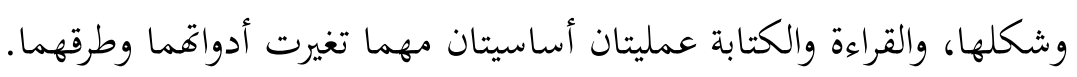

والمادة المتوفرة حول تاريخ التربية باللغة العربية ليست قليلة. لكن كثيراً منها يعود إلى كالى

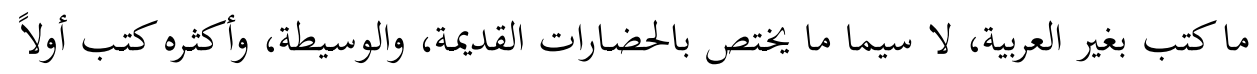

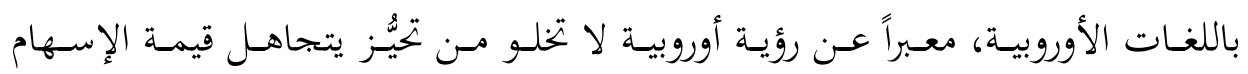

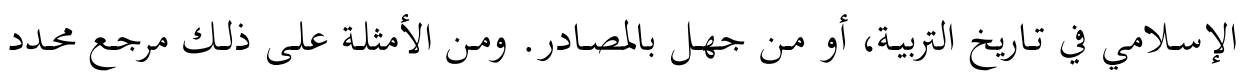

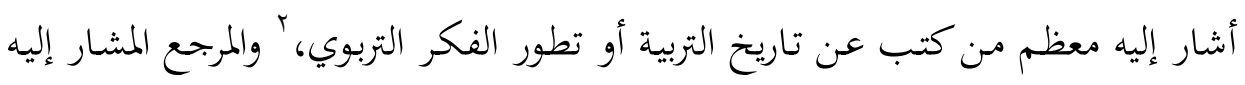

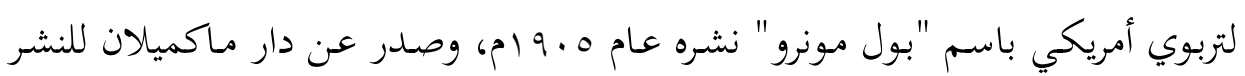

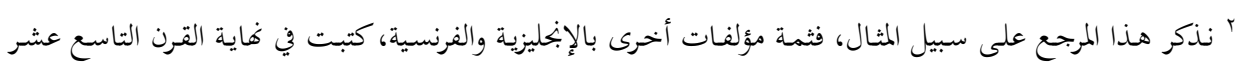

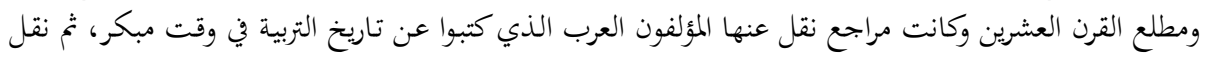

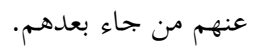




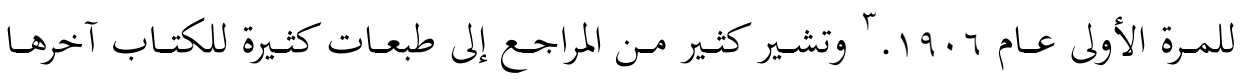

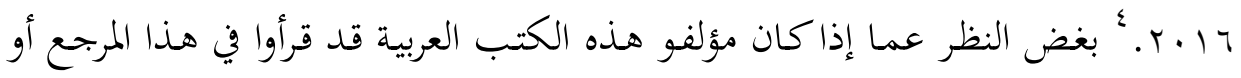
قرأوا ممن نقلوا عنه.

والكتاب بحلد ضخم بلغت صفحاته \& ام صفحة ويتصف بالشمول والاستقصاء في عرض تاريخي للفلسفات التي سادت العالم المعروف في التاريخ ابتداءً من تاريخ التعليم

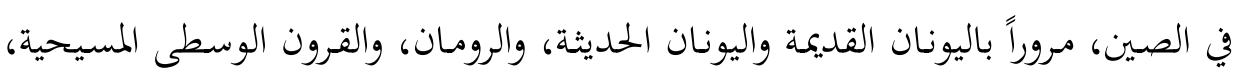

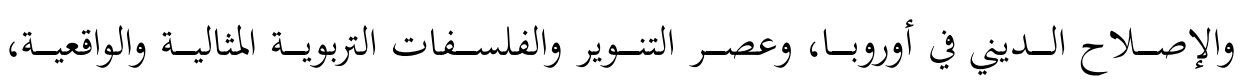
والتوجهات النفسية والعلمية والاجتماعية، والتوجهات الانتقائية المعاصرة (في فاية القرن

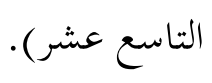

وخصص المؤلف فصلاً للتعليم في المحتمعات البدائية primitive مـ V V صفحة،

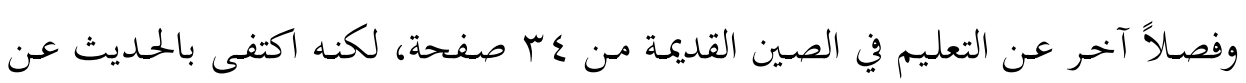
التعليم الإسلامي في ثلاث إشـارات عابرة تختص بأثر هذا التعليم على تطور التعليم في أوروبـا في العصور الوسطى. وجـاءت هذه الإشارات على الطريقة الاستشراقية المألوفة،

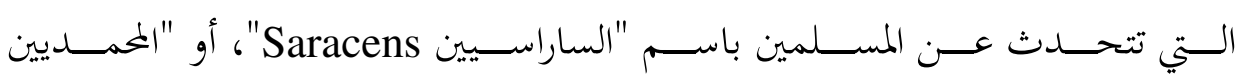
Mohammedans

${ }^{3}$ Monroe, Paul. A Text-Book in the History of Education, New York: The Macmillan Company, 1906.P. 160, 332

${ }^{4}$ Monroe, Paul (Died 1947). A Text-Book in the History of Education, Paperback, Sydney, Australia: Wentworth Press.-August 26, 2016.

$$
\text { • وردت الإشارة إلى هذا المرجع في عدد كبير من الأعمال نذكر منها ما يأتي: }
$$

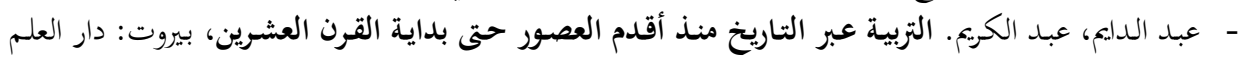

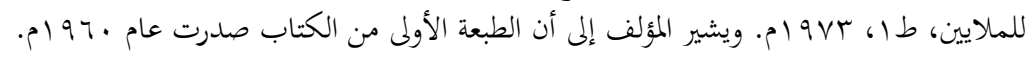

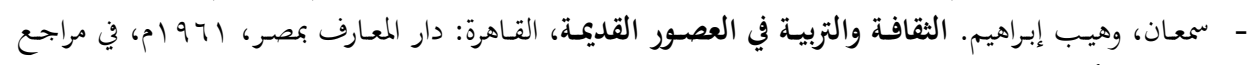

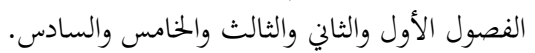

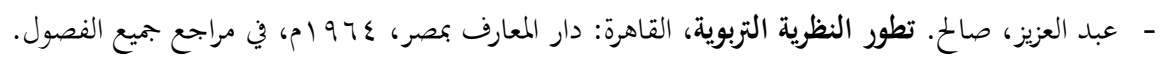

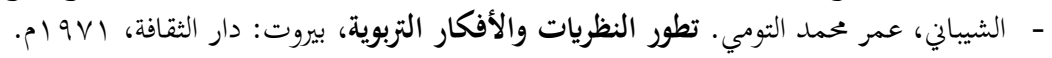

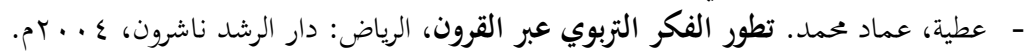


وجـاءت الإشـارة الأولى في جملة واحسدة في سياق بيـان أثر الترجمة العربيـة لأعمـال

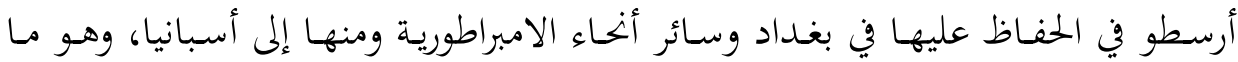

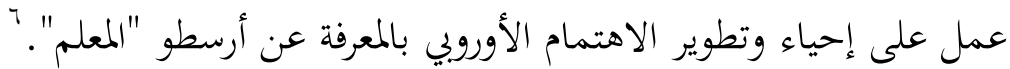

وجاءت الإشارة الثانية إلى المسلمين في ثلاث عبارات تفسر الأولى ظهور الجامعات الأولى في إيطاليا، وتحديداً في صورة مدرسة للطب في دير ساليرنو "مـن خهالال الاتصال

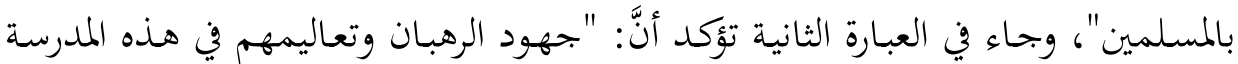

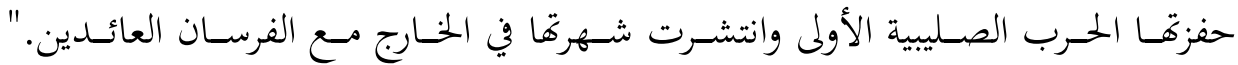

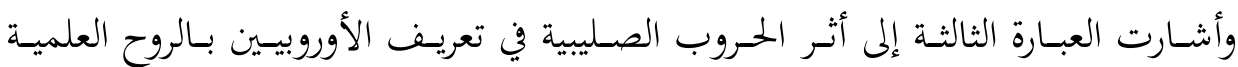

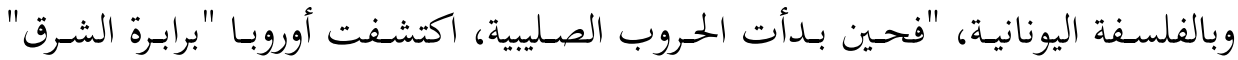

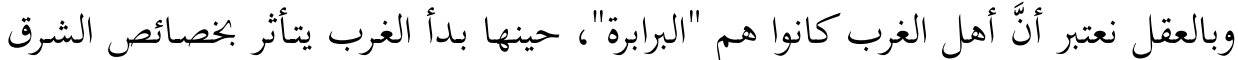

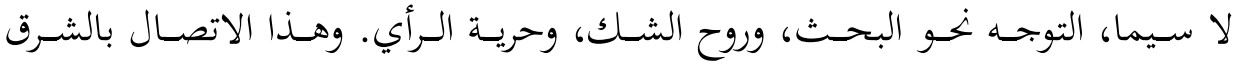
وبالتعليم الإسلامي قدَّم لأوروبا ليس فقط المعرفة بالثقافة العربية والعلم العربي (الذي كان ولتهان

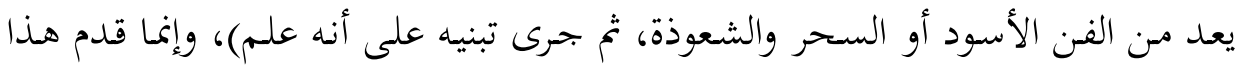

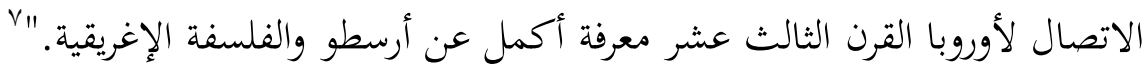
أمَّا الإشـارة الثالثة لذكر أثتر المسلمين، فقد تواصل عبر أربع صفحات تحت عنوان فرعي: "أثر تعليم المسلمين Influence of Saracen learning" حيث يقر المؤلف أن تاريخ التعليم في المجتمع المحمدي Mohammedan society، يطول شرحه لكن مـا

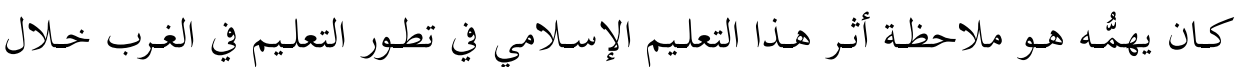

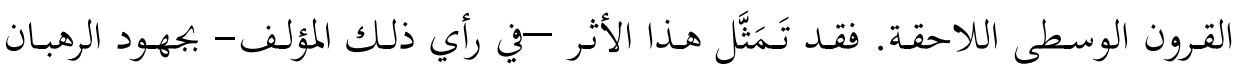
المسيحيين النسطوريين في غرب آسيا، فهم الذين اهتموا بالفلسفة الإغريقية بعد الأهمال

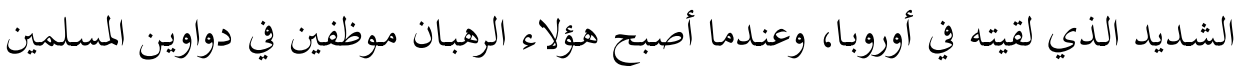

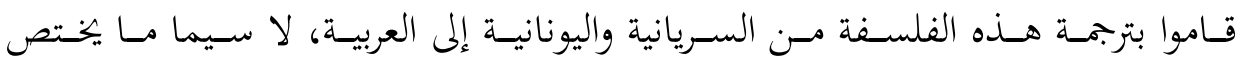
بالرياضيات والعلوم الطبيعية والطب، وتزايد هذا الاهتمام الفلسفي على يـد ابن سينا.

${ }^{6}$ Monroe, Paul. A Text-Book in the History of Education, op. cit., P. 160.

${ }^{7}$ Ibid. PP. 314-315. 
يقول المؤلف: "ويف الوقت الذي كانت المدارس المسيحية في شرق أوروبا وغربها تعاني من

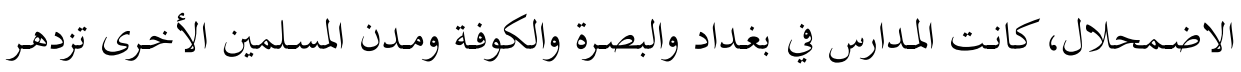
بنشـاط رائع وشهـرة كبيرة. وكانـت نوعيـة التطور الفلسفي الـذي تأسـس على أعمـال

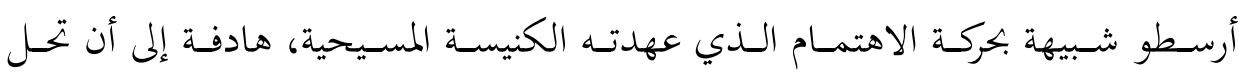

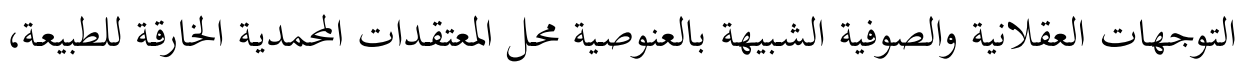
ثم لتطوير لاهوت وفلسفة بالاعتماد على التطورات اللاحقة لتعاليم أفلاطون وأرسطو. ." وقد لاقت هذه الفلسفة اعتراضات من النظرة المحمدية الأورثوذكسية "المحافظة" التي عرفتها الأورثوذكسية المسيحية، فاضطرت هذه الفلسفة إلى الهجرة إلى الشمال الأفريقي

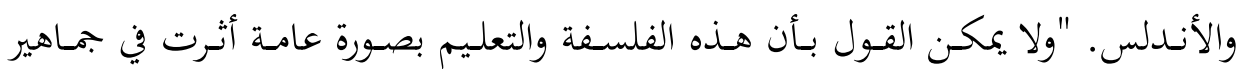

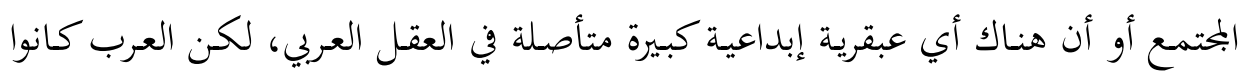

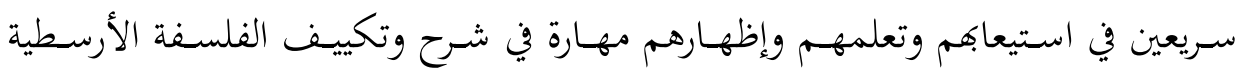

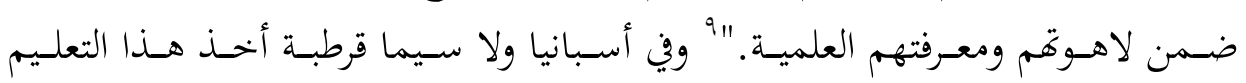
الأرسطي فيما بعد القرن العاشر يجد تطبيقات عملية ذكية. ففي جميع الممالك الإسلامية

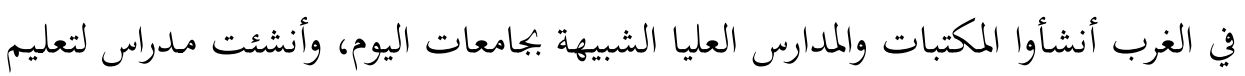

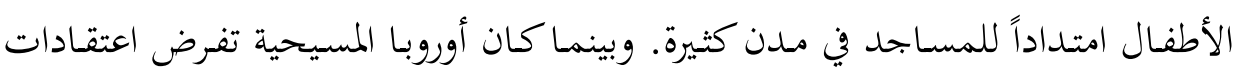
دينية حول فكرة الأرض المسطحة، كان مسـلمو الأندلس "moors" يعلمسون الجغغرافيـا مسن نماذج الكـرة الأرضـية. وعنـدما انتصـر المسـيحيون في النهايـة على المحمـديين حولهوا المراصد الفلكية إلى جرسيات كنائس. من هؤلاء العرب أخذا الأوروبيون في القرن العاشر

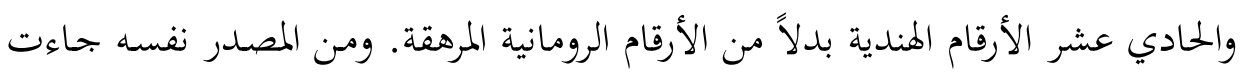

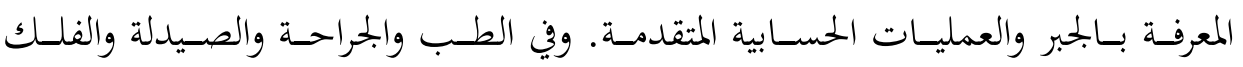

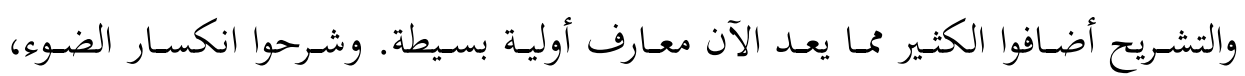

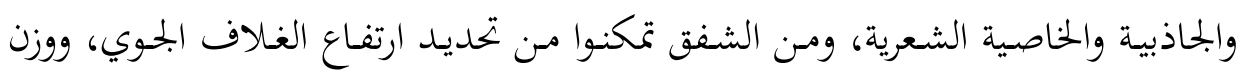

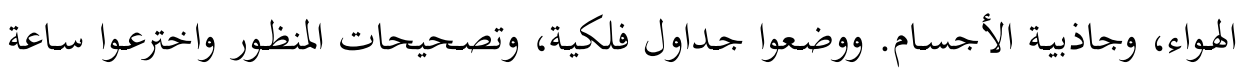

\footnotetext{
${ }^{8}$ Ibid., P. 331
}

${ }^{9}$ Ibid., P. 332. 


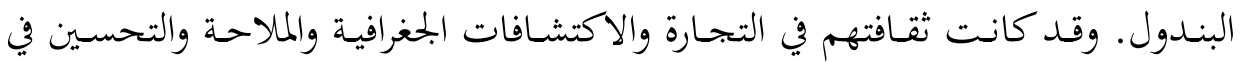

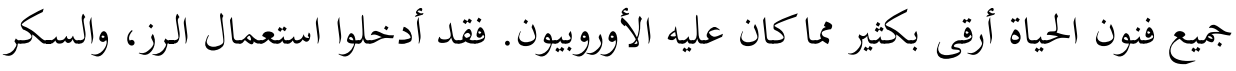
والقطن وإنتـاج الحرير، وعلمـوا الأوروبيـين استعمال البوصلة ومسحوق البـارود والمـدفع.

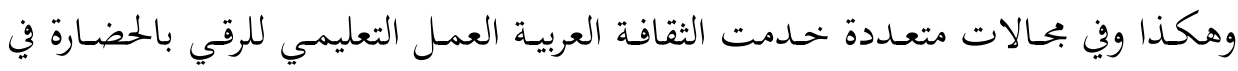

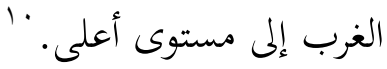

واستأنف المؤلف حديثه عن المؤثرات الإسهلامية على التعليم الأوروبي بالإشارة إلى الفكر الرُشْْدِيّ ' الذِي عرف في البداية على أنه فكر عقلاني، وهو لمُ يكن أكثر مـن تعليقات على فكر أرسطو، لكنه أصبح فكراً أوتوذكسياً محافظاً، وانتقل بهذه الصفة إلى الى الى الجحامعات الأوروبية في القرن الرابع عشر، حيث منعت الجامعات تعليم أي شيء يناقض

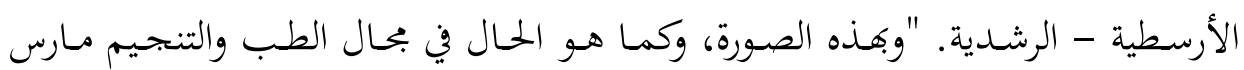
التعليم العـربي أثتره خهلال القـرون الوسطى، بعـد أن عـرف البحتمـع المحمـدي لفـترة طويلة

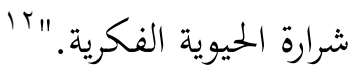

هنـا في هذا المقام أن نشير إلى أهمية النظر الموضوعي للمؤلفات الكثيرة التي تولت

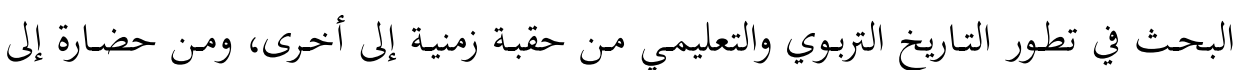
أخرى، والنظر الموضوعي لا يغني عن إعمال التحليل النقدي، للكشف عن التصورات الفكريـة والنظريـات التي حكمـت كتابـات المـؤلفين والبـاحثين في تطسور الفكـر التربـوي والممارسات التربوية، سواءً كانت هذه التصورات الفكرية تستند إلى مرجعية دينية أو غير دينية. فثمة نظريات حكمت طريقة الباحثين في التحقيب الزمني، ونظريات كرست فكرة التطور العضوي، ونظريات فسرت عملية التفكير البشـي عبر مراحل أوجسـت كونتت

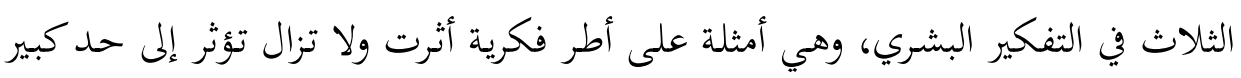

${ }^{10}$ Ibid., PP. 332-333

${ }^{11}$ Averroism

12 Ibid., PP. 333-334 


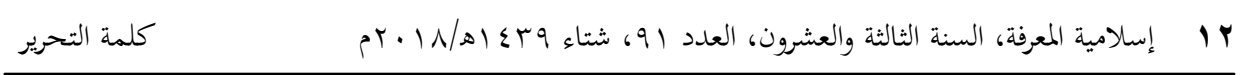

في تصسور البـاحثين والمؤلفين، وصفاً وتفسيراً، لماكانست عليـه حالـة التربيـة والتعليم في البحتمعات البشرية.

فميدان الفكر التربوي الإسلامي بحاجة ماسة إلى بناء رؤية تنطلق من هداية الوحي الإلهي، وتأخذ بالحسبان كلاً من الفطرة البشرية، وحقائق الواقع، وطبائع الأشياء. والله سبحانه الموفق لكل خحير. 